\title{
Gustavo Adolfo Bécquer, Gabriel de la Concepción Valdés und die späte Blüte der Romantik
}

Wenn wir in den folgenden Sitzungen, wenn wir in den folgenden Kapiteln über den Orbit der Literaturen im Zeichen der Romantik hinausgehen und die Romantik verlassen wollen, so können wir dies zum einen nicht in dem Sinne tun, dass wir eine Epoche dezidiert hinter uns lassen und das Kapitel ,Romantik‘ schließen. Wie schon zu Beginn unserer Vorlesung festgehalten wurde, verbindet uns nicht allein im Bereich der Liebe ${ }^{1}$ auch heute noch $\mathrm{zu}$ viel mit der Romantik, ist $\mathrm{zu}$ viel von ihr selbst noch in unseren Avantgarden präsent, als dass wir uns radikal einer anderen, etwa der finisekulären Ästhetik zuwenden könnten, um nichts mehr mit Romantikern zu tun zu haben. Denn selbst dort noch, wo sich Ästhetiken dezidiert gegen romantische Strömungen in Stellung brachten, blieb in der Ablehnung der Romantik noch unendlich vieles dem Romantischen verpflichtet.

Zum anderen können wir einen so verstandenen ,Abschied' vom Orbit der Romantik nicht allein aus einer französischen beziehungsweise französischsprachigen Perspektive betrachten, sondern müssen notwendig in den spanischsprachigen Raum wechseln, um einschätzen zu können, wie sich die literarischen Wechsel-Verhältnisse dort gestalteten. Wir tun dies zunächst innerhalb Europas, indem wir uns dem großen spanischen Dichter der späten Romantik zuwenden, Gustavo Adolfo Bécquer, dessen literarisches Leben im Sinne seiner Rezeption erst nach seinem Tod im Jahre 1870 richtig begann. In einem zweiten Schritt wollen wir parallel zu unserer Beschäftigung mit Gertrudis Gómez de Avellaneda dann den Sprung in die Neue Welt und nach Kuba wagen, wo wir mit Plácido auf neue Rhythmen und eine neue Musik in der Lyra, in der Lyrik der späten spanischsprachigen Romantik stoßen werden.

Das lyrische Schaffen des Gustavo Adolfo Bécquer war wie seine Rezeptionsgeschichte sicherlich von mancherlei Außerordentlichem geprägt, was Leben, Werk und Wirken des jung verstorbenen Poeten betrifft. Die späte Wirkung seiner Lyrik wie auch seiner Leyendas hat in den letzten Jahrzehnten vermehrt dazu geführt, in ihm - wie etwa bei Ángel Esteban² - einen Vertreter der Moderne im Sinne des Übergangs zum spanischen und hispanoamerikanischen Modernismo erkennen $\mathrm{zu}$ wollen.

1 Vgl. hierzu den zweiten Band der Potsdamer Vorlesungen in Ette, Ottmar: LiebeLesen, insb. S. 135-161 u. S. 677-726.

2 Vgl. hierzu u. a. Esteban, Ángel: La modernidad literaria de Bécquer a Martí. Granada: Impredisur 1991.

Ә Open Access. (C) 2021 Ottmar Ette, publiziert von De Gruyter. (c) BY-NC-ND Dieses Werk ist lizensiert unter einer Creative Commons Namensnennung - Nicht-kommerziell - Keine Bearbeitung 4.0 International Lizenz. https://doi.org/10.1515/9783110703443-029 
Gewiss, ein Vertreter der Moderne, so scheint mir, ist Gustavo Adolfo Bécquer allemal! Es handelt sich freilich um eine Moderne, die noch nicht aus jener wenige Jahrzehnte später erkennbaren Beschleunigung heraus das lyrische Schreiben des Dichters entfaltete, das der Romantik in Spanien und Hispanoamerika mit gewissen zeitlichen Verzögerungen eine Art ,zweiter Luft‘ verschaffte und der literarischen Produktion der zweiten Hälfte des 19. Jahrhunderts eine neue Phase an die Seite stellte. In jedem Falle aber ist es wichtig, die wenigen biographischen Fakten aus dem Leben des mit vierunddreißig Jahren recht jung verstorbenen Lyrikers kurz zu beleuchten, haben sie doch in der Stilisierung und Selbststilisierung zu einem tragischen Romantikerleben die Rezeption seiner Gedichte, Texte und Schriften nicht unwesentlich geprägt.

Gustavo Adolfo Bécquer alias Gustavo Adolfo Domínguez Bastida wurde am 17. Februar 1836 in Sevilla geboren und verstarb am 22. Dezember 1870 in Madrid. Bereits sein Vater, der ein angesehener spanischer Maler war, hatte auf den Namen seiner holländischen Vorfahren, die Jahrhunderte zuvor nach Sevilla eingewandert waren, als Künstlername zurückgegriffen. Das Leben des künftigen Dichters war von Schicksalsschlägen gesäumt: Nachdem er seine Mutter im Alter von fünf Jahren verloren hatte, wurde er schon mit neun Jahren nach dem Tod seines Vaters Vollwaise und blieb in der Obhut seiner zärtlichen „Madrina“, seiner Taufpatin. Auch in seinem späteren Leben häuften sich die Unglücksfälle.

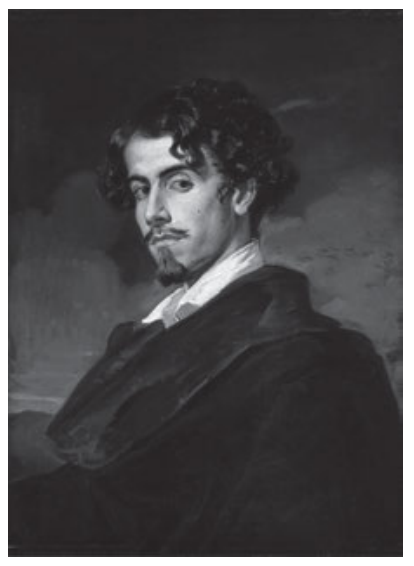

Abb. 65: Gustavo Adolfo Bécquer (Sevilla, 1836 - Madrid, 1870).

Gustavo Adolfo liebte Musik und Malerei, weit mehr als alles andere aber die Literatur. Rasch wurde die Lektüre zu seinem tröstlichen Zufluchtsort. Im Alter von achtzehn Jahren - eine Ausbildung bei einem spanischen Maler hatte er abgebrochen - nahm er in der Hauptstadt Spaniens ein Literaturstudium auf und versuchte, zusammen mit seinem Bruder Valeriano einen Weg zum literarischen 
Ruhm zu finden. Sein Bruder, der auch ein ausgezeichneter Maler war, half ihm auch später als Freund in vielen schwierigen Situationen. Doch der ersehnte Ruhm blieb aus. Er veröffentlichte Artikel in lokalen Zeitschriften und Zeitungen, schrieb für die Dirección de Bienes Nacionales und versuchte, sich in Madrid über Wasser zu halten.

Doch bereits 1858 war er wieder in Sevilla, wo er wohl an Tuberkulose, möglicherweise aber auch an Syphilis erkrankte. Seine 1861 geschlossene Ehe wurde unglücklich, so dass sich das Paar, dem zwei Kinder entstammen, bald trennte. Interessanterweise arbeitete Bécquer von 1864 bis 1868 als Romanzensor, der freilich nachlässig verfuhr und mit der Revolution von 1868 auch noch diese, literarische‘ Arbeit verlor. Bécquer war überaus schüchtern und lebte zurückgezogen, trug ärmliche Kleidung - und niemand hätte in ihm den bald aufgehenden großen Stern der spanischen Romantik vermutet. Erst nach seinem Tod im Alter von vierunddreißig Jahren in Madrid nahmen die Zeitgenossen sein Schaffen zur Kenntnis, veröffentlichten postum seine Gedichte und ,Legenden“. Der Aufstieg von Bécquer nahm seinen Lauf, sein Ruhm stieg stetig und verwandelte ihn postum zum neben Gertrudis Gómez de Avellaneda und Espronceda großen Vertreter der spanischen Romantik.

Die literarischen Schöpfungen von Gustavo Adolfo Bécquer waren von großer poetischer Suggestivkraft und erschienen wie ,naive“ romantische Schöpfungen zu einer Zeit, als die Romantik im Grunde schon nicht nur im Rest Europas, sondern auch in Spanien vergangen war. Nur wenige seiner Gedichte erschienen zu Lebzeiten; doch die scheinbare Naivität seiner Liebesdichtungen faszinierte ein breites Publikum, das sich im Schicksal des ,verkannten Poeten“ spiegelte. Der schlichte Titel Rimas oder Reime wurde in Spanien und der spanischsprachigen Welt rasch unsterblich. Bei seinen ebenfalls postum herausgegebenen Leyendas oder Legenden handelt es sich im Grunde um unerhörte Begebenheiten, um Novellen, die oft mit hypnotischen Phänomenen und Angstzuständen zu tun haben und später als Vorläufer einer phantastischen Literatur gelesen wurden. Daneben verfasste der Dichter seine Cartas desde mi celda, seine Briefe aus meiner Zelle von 1864 sowie eine Reihe unterschiedlicher Artikel, darunter Reisenotizen, kostumbristische Szenen, Buchbesprechungen oder archäologische Studien.

Das Zentrum und Herzstück seines großen Schaffens bilden bis heute aber seine Rimas, die ihren Titel erst von den postumen Editoren erhielten. Auch wenn einige wenige Gedichte in damaligen Periodika schon erschienen waren und ein kleines Publikum erreichten, darf doch als eigentliche Initialzündung seines Erfolgs die Versammlung von Künstlerfreunden am Tag nach seinem Begräbnis gewertet werden. Denn diese Gruppe beziehungsweise Versammlung entschloss spontan, eine Finanzierung einer Ausgabe von Bécquers Gedichten und Erzäh- 
lungen in Angriff zu nehmen. Die finanziellen Erträge dieser Publikation sollten der wirtschaftlich gefährdeten Familie Bécquers zugutekommen.

Die Wirren um diese Publikationsgeschichte beginnen noch zu Lebzeiten Bécquers mit den Ereignissen um die Revolution von 1868 und setzen sich in deren Niederschlagung und dem Ende der Ersten Spanischen Republik fort. Wenn wir uns dies vor Augen halten, dann können wir erkennen, dass das postume Schicksal eines ,verkannten Dichters“ von vielen Zufällen und damit - im Sinne Balzacs vom größten Romancier der Welt abhängig ist. Das Projekt der Rimas ging in all diesen Wirren seiner Publikationsgeschichte nicht verloren und brachte letztlich den großen spanischen Dichter hervor, als welcher Gustavo Adolfo Bécquer heute vor uns steht. Die zahlreichen Büsten und Statuen des großen Poeten, auf die man nicht nur in Sevilla, sondern in ganz Spanien stoßen kann: Sie alle hätte es nicht gegeben, hätte nicht der Zufall eingegriffen in Gestalt der Initiative einiger Freunde der notleidenden Familie. Denn der Gedichtband erschien nun im Jahre 1871 und bildet so etwas wie den Schluss- und Höhepunkt zugleich der spanischen Romantik, welche in den dreißiger Jahren so intensiv eingesetzt hatte und als deren frühe Vertreterin wir die kubanische und spanische Dichterin Gertrudis Gómez de Avellaneda kennengelernt hatten. Zu ihren begeisterten Lesern zählte auch Gustavo Adolfo, der ihr nicht nur in einem Gedicht seiner Rimas huldigte.

Noch einmal kurz zu den Wirren um diese Gedichte des spanischen Barden! Sie entstanden seit 1856 und damit anderthalb Jahrzehnte vor dem Erscheinen des Bandes. Die noch von Bécquer besorgte Zusammenstellung ging 1868 im Chaos der Revolution verloren, und Bécquers Dichterfreunde rekonstruierten den Band unter Rückgriff auf das sogenannte Spatzenbuch, das Libro de los gorriones, das neunundsiebzig Gedichte enthielt. Auch dieses Buch ging verloren, wurde später aber wieder gefunden und zählt zu den großen Reliquien der Bécquer-Forschung. Mit den näheren Umständen der Gedichtauswahl können wir uns an dieser Stelle nicht beschäftigen. Die Anordnung der Rimas jedenfalls folgt der Anordnung zu einer fiktiven Liebesgeschichte, wie dies beim bedeutendsten europäischen Liebeslyrik-Zyklus bereits der Fall war: Petrarcas Le Rime. Wir haben es also mit einer fiktiven Liebesgeschichte zu tun, die nachträglich autobiographisch unterfüttert wurde, die wir aber keinesfalls für bare Münze nehmen dürfen.

Und worum geht es in dieser erfundenen Liebesgeschichte? Ich darf ihre wichtigsten Züge kurz skizzieren: Anders als beim petrarquistischen Vorbild führt die wohlmeinend arrangierte Liebe freilich zur Erfüllung, macht aber nicht bei ihr Halt. Dichtungstheoretischen Versen und Anrufungen an das dichterische Genie folgen Gedichte, welche die idealisierte und scheinbar unerreichbare Frau zelebrieren. Dem vielstimmigen Feiern der Geliebten folgt die überraschende Erfüllung der Liebe. Dann jedoch kommt es zum Bruch zwischen den Liebenden und es bleibt die Erinnerung an das so rasch vergangene Liebesglück. Dem Lie- 
besschmerz folgen Vorwürfe an die einst so sehr vom lyrischen Ich idealisierte Frau sowie Selbstvorwürfe eines Ich, das in Einsamkeit und Melancholie versinkt. Reflexionen über das Leben und Bilder des Todes schließen die Rimas ab. Soviel zum inhaltlichen Spannungsbogen.

Wesentlich am Erfolg der Rimas war die überzeugende Fiktion beteiligt, es handle sich bei diesen Gedichten um die lyrische Darstellung des Liebeslebens des Dichters, der seine intimsten Erlebnisse und Gefühle festgehalten habe. Doch ach, es handelt sich nicht um Erlebnislyrik, sondern um geschicktes Arrangement! Dies freilich mag manche autobiographischen Projektionen einer hingerissenen Leserschaft unterlaufen: Die Liebesgeschichte selbst jedoch macht dies nicht schlechter. „Se non è vero, e ben trovato“: Gut erfunden hält besser!

In Wirklichkeit war Gustavo Adolfo Bécquer ein die Liebeslyrik intensiv reflektierender, sie mit zahlreichen intertextuellen Verweisen an Heinrich Heine, Alphonse de Lamartine oder Victor Hugo versehender Lyriker, der es verstand, einen Erzählzyklus in Gang zu setzen, der die Erwartungshaltungen seiner Leserschaft erfüllte. Die Rimas sind fast schon ein Rückblick auf die Romantik und die sie speisenden Quellen der gesamten europäischen Dichtungstradition. Wir haben es folglich mit einer selbstreflexiven und intertextuell hochverdichteten Liebeslyrik zu tun, die im Gewand von Erlebnislyrik daherkommt. Eine Fingerübung in lyrischer Rhetorik, meinen Sie? Ja, aber eine auf höchstem Niveau; und zugleich eine, die uns noch einmal das Panorama romantischen Liebes- und Seelenschmerzes vor Augen führt und zu Gehör bringt. Die Krankheiten und der frühe Tod des Dichters aus Sevilla taten ein Übriges, die ,Legende Bécquer‘ sowie die autobiographischen Lesarten zu bestärken.

In seinem Vorwort $\mathrm{zu}$ der noch von ihm geplanten Gedichtsammlung des Spatzenbuches hob Bécquer eine Reihe für sein Schaffen zentraler Aspekte hervor, die uns zugleich erneut daran gemahnen, dass die Romantik das Andere der Vernunft betonte und gerade auf der Schattenseite des eigenen Ich suchte - oder wie wir heute mit Sigmund Freud sagen könnten: im eigenen Unbewussten. Wir stoßen mit Bécquer zur Nachtseite unserer Vernunft vor.

Aus dieser Konstellation ergeben sich gerade in der Dichtkunst eine Reihe poetologisch entscheidender Fragen, die von Bécquer in der Tat auch problematisiert und erörtert wurden. Ich möchte Ihnen aus dieser Introducción einen kurzen Auszug präsentieren. Auf eine dramatische Weise laufen nämlich bei dem äußerst belesenen Dichter, der selbstverständlich auch die großen Franzosen von Chateaubriand über Musset bis Lamartine und Vigny kannte, der sich daneben vor allem aber an der deutschen Romantik und insbesondere an Heinrich Heine in französischen und spanischen Übersetzungen orientierte, ein letztes Mal die Fäden der europäischen Romantik zusammen. Dass dieses späte Zusammenlaufen in den fünfziger und sechziger Jahren des 19. Jahrhunderts ausgerechnet 
in Spanien erfolgte, wo die Bécquer-Rezeption sich ab den siebziger Jahren entfaltete, war gewiss kein Zufall. Denn die ehemalige Kolonialmacht Spanien war zu diesem Zeitpunkt längst auch in literarhistorischer Hinsicht an den Rand des damaligen, mit wiederholten Schüben einer sozioökonomischen Modernisierung konfrontierten Europa gerückt:

In den dunklen Ecken meines Gehirns schlafen, zusammengekuschelt und nackt, die extravaganten Kinder meiner Phantasie und warten schweigend darauf, dass die Kunst sie mit dem Worte bekleide, um sich anständig auf der Bühne der Welt zu präsentieren. [...]

Und hier drinnen, nackt und unförmig, durcheinander- und in einer unbeschreiblichen Konfusion zusammengewürfelt, fühle ich sie bisweilen, wie sie sich regen und ein dunkles und seltsames Leben leben, das dem jener Myriaden von Keimen ähnelt, die in einer ewigen Inkubation tief im Inneren der Erde kochen und erzittern, ohne doch ausreichend Kräfte zu finden, um an die Oberfläche zu gelangen und sich unter dem Kusse der Sonne in Blumen und Früchte zu verwandeln.

Sie begleiten mich, dazu verurteilt, mit mir zusammen zu sterben, ohne dass von ihnen eine andere Spur bliebe als jene, die ein mitternächtlicher Traum hinterlässt, den man des morgens schon nicht mehr erinnert. Bei mancherlei Gelegenheiten und bei dieser schrecklichen Vorstellung zumal rebelliert in ihnen der Lebensinstinkt, und sie suchen in Horden, erregt in schrecklichem, wenn auch schweigendem Tumulte, aus den Finsternissen, in denen sie leben, heraus und wo auch immer ans Licht zu gelangen. Aber ach!, zwischen der Welt der Idee und jener der Form existiert ein Abgrund, den allein das Wort zu überbrücken vermag, und das Wort, schüchtern und schläfrig, verweigert sich, ihren Anstrengungen beizustehen. Stumm, stumpf und ohnmächtig fallen sie nach dem unnützen Kampfe wieder in ihren alten schlammigen Marasmus zurück. So fallen die gelben Blätter untätig in die Furchen der Wege, sobald der Wind aufhört, jene Blätter, die ein Wirbelwind einst gejagt! [...] Ich begehre, mich ein wenig mit der mich umgebenden Welt zu beschäftigen, könnt' ich, erst einmal leer geworden, die Augen abwenden von jener Welt, die ich in meinem Kopfe trage. Der gemeine Sinn, welcher die Haarspange der Träume ist, beginnt zu wanken, und die Leute aus verschiedenen Lagern verbinden und vermischen sich. Es macht mir Mühe zu wissen, welch Dinge ich geträumt und welche mir widerfuhren. Meine Affekte verteilen sich zwischen Phantasmen der Einbildungskraft und realen Gestalten. Mein Gedächtnis klassifiziert die durcheinander gehenden Namen und Daten von Frauen und Tagen, welche gestorben sind oder die mit den Daten und Frauen vorübergingen, die niemals außerhalb meines Denkens existiert. Es tut not, uns endlich ein für alle Mal vom Kopfe auf ewig herunterzustürzen. $^{3}$

In dieser langen Passage - und aus diesem Grunde wollte ich sie Ihnen auch vor Augen führen - steckt viel von Bécquers Bilderwelten. Das abschließende Bild kennen Sie schon: das Bild von den Blättern im Herbst, die stets nicht allein den

3 Bécquer, Gustavo Adolfo: Rimas; Leyendas escogidas. Hg. Rubén Benítez. Madrid: Taurus 1990, S. 61-63. 
Hinweis auf ein Lebensalter und einen zu Ende gehenden Lebenszyklus, sondern auch auf die Blätter des Schreibenden enthalten, also autoreferentiell und potentiell poetologisch sind. Wir haben in dieser Wendung Bécquers also ebenfalls ein Bild, wie es topisch schon Lamartine am Ende seines Gedichtes zu beschreiben suchte. Und bei beiden romantischen Dichtern dominiert die Einsamkeit des Ich, das sich mit den eigenen Bildern der Welt umgibt und bald nicht mehr zu unterscheiden vermag, welches der realen Welt entnommen und welches erträumt ist.

Erneut haben wir das „extraño“, die „extrañeza“ als einen Bezugspunkt für das dichterische Ich, das sich freilich mit den dunklen Seiten seiner Topographie, den dunklen Windungen seines eigenen Gehirns beschäftigt. Dabei gilt es, die Lichtmetaphorik und Nachtmetaphorik, die ganz zweifellos in Spanien noch unter dem Einfluss etwa der Caprichos von Francisco de Goya und insbesondere unter seinem großartigen Werk El sueño de la razón produce monstruos stehen, ${ }^{4}$ ebenso als künstlerische und philosophische Denk- und Ausdrucksmöglichkeiten zu begreifen wie die Metaphorik der Nacktheit, die in dieser Passage gleich zweimal erscheint. Dies verweist auf die doppelte Bedeutung von Nacktheit in der jüdisch-christlichen Kulturtradition des Abendlandes: zum einen das Bedeutungselement des Unverfälschten, Direkten und Paradieshaften und zum anderen das Element des Verdorbenen, nicht Zeigbaren, Unzivilisierten und nicht Präsentierbaren. Wir befinden uns im Kopf des Dichters zweifellos auf der Nachtseite der Vernunft und nicht im Hirn einer klaren, lichtvollen Rationalität.

Und doch sprießen hier überall Ideen und Keime von Vorstellungen, die jedoch nicht ans Tageslicht, an die Oberfläche gelangen können. Diese Ideenkeime bleiben in der Latenz und schaffen es nicht, sich dauerhaft manifestieren zu können. Die Welt dieser Ideen ist vielfach an den Bereich des geologischen Erdinnern mit seinen Magmen und Gesteinsschmelzen, aber vor allem an Metaphern aus dem agrikulturellen Feld und damit an den zentralen kulturellen Bereich des Abendlandes gekoppelt. Daraus entwickeln sich organizistische Metaphorologien weiter, die ein organisches Wachstum miteinblenden, welches in seiner Existenz immer bedroht ist. Denn diese Metaphern und Bilder können so verschwinden, wie ein nächtlicher Traum am Morgen nicht mehr erinnerbar scheint.

Zugleich wird auch der Schlamm, der „marasmo“, deutlich markiert und erscheint in seinen Traditionen seit Platon als Urschlamm, aus dem sich das Leben erhebt und bildet. Doch kann dieses dem Urschlamm, dem Chaos entris-

4 Vgl. hierzu Ette, Ottmar: Miedo y catástrofe / Miedo ante la catástrofe. Sobre la economía del miedo de cara a la muerte. In: Ette, Ottmar / Naranjo Orovio, Consuelo / Montero, Ignacio (Hg.): Imaginarios del miedo. Estudios desde la historia. Berlin: Verlag Walter Frey - edition tranvía 2013, S. 11-44. 
sene Leben nicht einfach in Kunst überführt werden und als Kosmos, folglich als Ordnung und Schönheit erscheinen. Denn das Wort des Dichters, „la palabra“, steht diesem nicht einfach zu Diensten, sondern verweigert sich oft, wo die Ideen im Gehirn sich in Worte umzuformen suchen.

Denn da ist ja der Übergang von der Idee zur Form, ohne die keine Kunst Kunst sein kann und keine Kunst der Welt auskommt. Es geht folglich um die künstlerische Bearbeitung eines künstlerischen Artefakts, das der Idee die ihr entsprechende Form geben muss. An diesem kritischen Punkt zeigt sich die Schwierigkeit, die immateriellen Vorstellungen, Ideen und Bilder, die hier mit dem Bereich des Traumes und der Traumbilder gekoppelt werden, in einen Zusammenhang zu bringen mit dem künstlerischen, mit dem literarischen Schaffensprozess. Vergessen wir nicht, dass Bécquers Bruder wie sein Vater angesehene Maler waren und dass er selbst eine Ausbildung im Atelier eines spanischen Malers abgebrochen hatte! Doch nicht die Bilder, sondern allein die Worte sind in der Lage, diese Brücke über den von Bécquer aufgezeigten Abgrund zu schlagen, also die eigentliche Kunst als Wortkunst erstehen zu lassen und mit dem Pinsel der Literatur aufkeimenden Ideen Ewigkeit zu verleihen.

Allein auf diese Weise war es Gustavo Adolfo Bécquer möglich, die dunkle Welt des Gehirns zum Vorschein zu bringen, jenes widersprüchliche, irrationale Leben, das die andere Seite der Vernunft darstellt und für deren Ausdruck nun in erster Linie der Dichter, der Künstler des verdichteten Wortes, verantwortlich ist. Die Romantik erschließt jene Nachtseite der Vernunft, welche später die historischen Avantgarden und insbesondere die Surrealisten so sehr anzog. In diesem Zusammenhang wird deutlich, dass Bécquer bezüglich der Hierarchie der Künste ohne Frage der Wortkunst und insbesondere der Lyrik die erste Stelle im System aller Künste einräumt. Die verdichtete Wortkunst ist in der Lage und allein fähig, diesen tiefsten Innenraum des Unbestimmten und Unbestimmbaren, das sich nicht auf den Begriff bringen lässt, auszuloten. Literatur ist eine in Bewegung gesetzte Polylogik, welche selbst die Logiken des Irrationalen zu erschließen und sinnlich erfahrbar zu machen vermag.

Der Kopf, das Gehirn des Dichters, ist damit keineswegs der Sitz von Vernunft und Rationalität allein. Das Hirn macht nicht nur die vernunftgemäße Transparenz, sondern auch die Nachtseite des Irrationalen zugänglich. Innenraum und Außenraum, Raum der Träume und Raum der Kunst, sind dabei nur durch den Künstler in einer exteriorisierenden Bewegung miteinander über den Abgrund zwischen Idee und Form hinweg miteinander zu verbinden. Die genealogische Verbindung, die in den ackerbaulichen Metaphern ebenfalls schon außermenschlich präsent ist, wird in dieser Passage auch auf die Ebene der menschlichen Genealogie bezogen, insoweit diese huschenden, nicht fassbaren Ideen die Kinder, die „hijos“ des lyrischen Ich sind. Sie sind seine Erzeugnisse, seine Produkte, ohne 
dass er doch eine selbstverständliche Verfügungsgewalt über diese seine Kinder hätte. Denn sie führen ihr Eigen-Leben, folgen ihren eigenen Lebens-Logiken.

Nicht immer aber ist eine Unterscheidung von Innenwelt und Außenwelt gegeben, denn immer ist das Andere, die andere Welt, der „otro mundo“ in der realen Welt mitenthalten: Sie sind beide Teile meines Gehirns und ich kann beide nicht voneinander trennen und ablösen. Was ist Fiktion, was Realität? Was ist Dichtung und was Wahrheit? Alles vermischt sich; und der Dichter macht klar, dass es nicht darum gehen kann, die wahren Tage und Frauenbegegnungen von den imaginierten zu unterscheiden. Er macht damit unmissverständlich klar, dass seine Lyrik, ja selbst die Erzählsubstanz seiner Gedichte nicht auf das Erlebte, nicht auf die autobiographische Dimension seiner Findungen und Erfindungen reduziert und als Erlebnislyrik fehlgedeutet werden darf. Der romantische Gestus des Hinauswerfens, der scheinbaren Unbehandeltheit aber ist noch präsent, selbst wenn er zuvor durch den Verweis auf die notwendige Bearbeitung durch den Künstler erheblich relativiert worden war. Doch ist es der Traum oder ist es der Schlaf der Vernunft, so ließe sich mit Goya fragen, der die Ungeheuer, der die Monstren hervorbringt?

Die unverkennbar stark rhetorisch geprägte Strukturiertheit der Rimas zeigt in aller wünschenswerten Deutlichkeit auf, wie sehr der spanische Dichter sein Wortmaterial durcharbeitete und sich keineswegs einer freien ,Inspiration“ überließ. Dafür sprechen auch die zahlreichen intertextuellen Verweissysteme, welche diese Spatzengedichte - ungeachtet ihrer scheinbaren Spontaneität - gerade mit der romantischen Lyrik seiner Zeit verknüpfen. Die Vorliebe für topische Metaphern, Vergleiche, Parallelismen, zwei- und dreigliedrige Korrelationen, aber auch die Berücksichtigung und Beachtung metrischer Zwänge wie etwa der Silva oder der Octava real machen auf die Konstruktionsprinzipien der lyrischen Verdichtungsformen aufmerksam. Vorsichtig löst sich der Dichter von vorherrschenden Formen der Metrik, eine Loslösung etwa in der Form plurimetrischer Verse, die wir allenthalben in der romantischen Dichtung der romanischen Literaturen beobachten können, die sich aber erst in der im nachfolgenden Kapitel $\mathrm{zu}$ besprechenden Dichtkunst entschieden auf neue, radikale Formgebungen öffnet. Das vielleicht eindrücklichste Faszinosum der Rimas bildet zweifellos die lyrische Darstellung semantischer Unbestimmbarkeitsgefühle, von Übergängen zwischen Liebe und Schmerz, zwischen Liebessehnsucht und Todesstreben, zwischen Idealisierung und scharfer Detailbeobachtung der außersprachlichen Wirklichkeit.

Gewiss stehen die Rimas auch in der Tradition bestimmter Formen der andalusischen Volkspoesie, mit denen der Dichter aus Sevilla ebenso spielt wie mit Anklängen des spanischen Siglo de Oro. Doch der innerliterarische Raum, den seine Gedichte eröffnen, schließt ebenso die Dichtungen der romanischen 
Sprachen, insbesondere das Französische und Italienische, wie auch die Lyrik der englischen oder deutschen Romantik mit ein. Die Rimas bilden auf diese Weise einen unbezweifelbaren Höhepunkt romantischer europäischer Dichtung zu einem Zeitpunkt, zu dem sich andernorts in Europa unter dem Druck sozioökonomischer Modernisierung die Gewichte auch in der Dichtkunst längst verlagert hatten. Gustavo Adolfo Bécquer war als spanischer Dichter ein Romantiker, der gleichwohl Wege aus der Romantik wies. Dass er spätere spanische Dichter wie Jorge Guillén oder Rafael Alberti, aber gewiss auch einen tief im Andalusischen verwurzelten Dichter wie Federico García Lorca nicht unwesentlich prägte, steht gerade was die Bilder von der Nachtseite der Vernunft angeht - außer Frage.

Aus Gründen zeitlicher und räumlicher Begrenzung müssen wir leider auf eine Besprechung von Bécquers Leyendas verzichten, die sich aus mittelalterlichen, aber auch aus arabischen und juden-christlichen Quellen speisen und eine lange Tradition von „Tradiciones“ aufweisen, welche nicht nur mit dem Märchen- und Liedgut in Deutschland, sondern gerade auch im spanischsprachigen Bereich Europas und Amerikas weite Verbreitung fand. Ich möchte Ihnen dagegen zumindest zwei von Gustavo Adolfos dichterischen Schöpfungen vorstellen, die sicherlich zu den bekanntesten und meistzitierten Hauptwerken der spanischen Lyrik nicht nur des 19. Jahrhunderts gerechnet werden.

Ungezählt sind die Ausgaben der Rimas im spanischsprachigen Raum bis heute. An erster Stelle in den meisten davon finden Sie das Gedicht Yo sé un himno gigante y extraño, das ich Ihnen im Folgenden kurz vorstellen möchte:

\footnotetext{
Ich weiß einen großen, rätselvollen Hymnus,

Der in der Nacht der Seele den Morgenschein kündet,

Und diese Seiten entstammen jenes Hymnus'

Kadenzen, die in der Schatten Lüfte münden.

Ich wollt ihn schon schreiben, vom Manne,

Der die rebellische, listige Sprache zähmt

Mit Worten, die im gleichen Klange

Seufzer wären und Lachen, wie Noten gefärbt.

Doch vergeblich ist der Kampf; keiner Chiffre Töne

Alles in sich schlösse, aber - Du schöne!

Wenn Du in meinen Händen die Deinen,

Ins Ohr ich Dir sänge stets in Reimen. ${ }^{5}$
}

5 Bécquer, Gustavo Adolfo: Rimas; Leyendas escogidas, S. 65. 


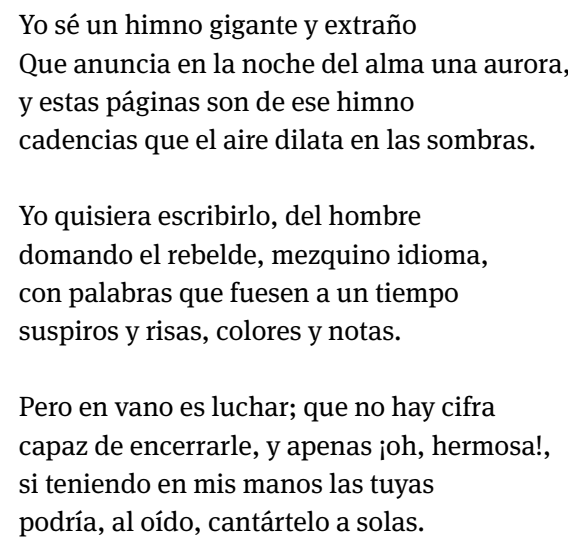

Vergleicht man die unterschiedlichen Ausgaben dieses Gedichts miteinander, so erkennt man sofort, dass unterschiedliche Fassungen in unterschiedlichen Ausgaben in Spanien kursieren. Doch wir wollen uns auf diese verlegen, die mir am wahrscheinlichsten erscheint, sind hier die Versgrenzen doch zugleich die Satzgrenzen und bedient sich auch die Reimart in Assonanzen einer Spannbreite, die ich in meiner Übersetzung nachzuahmen mich bemühte. Denn dieser Hymnus, diese Anrufung der Schönen spielt mit den Abweichungen von der Norm und den dichterischen Zwängen und lässt zugleich erkennen, dass hier ein Dichter schreibt, der sich im Vollbesitz seiner kreativen Kräfte weiß.

Das dreistrophige Gedicht versucht, die poetologischen Überlegungen, wie sie im Vorwort von Bécquer paratextuell dargelegt wurden, nun in Gedichtform mit der Problematik der Liebe zu verbinden. Zudem wird das Gedicht selbst zu einem Teil jenes gewaltigen und fremdartigen Hymnus, der nicht in die Präsenz der Kunst überzuführen ist, den aber gleichwohl die Liebe als intimste Kommunikationsform in der Engführung von Du und Ich wohl noch zu bergen vermöchte. Denn der sperrige, kantige Auftakt-Vers verwandelt sich im weiteren Verlauf des Gedichts in die melodische dritte Strophe, die mit einem Vers aus der nächsten Nähe von Du und Ich sein musikalisches, sein synästhetisches Ende findet.

Die ko-textuelle Position des Gedichts unmittelbar nach der Introducción sinfónica ist keineswegs zufällig und macht bezüglich der Umsetzung theoretischer Prämissen Sinn, auch wenn auf dieser Ebene einzuräumen ist, dass diese Schöpfung im Original wohl nicht an erster Stelle stand und keineswegs in allen Ausgaben der Rimas unmittelbar der Einführung folgt. Doch die Stellung dieser drei Strophen im Verhältnis zu allen anderen im Gedichtband abgedruckten Gedichten - also kurz: die Ko-Textualität - zeigt deutlich an, dass es hier um eine poetologische Programmatik geht, welche nach einer herausgehobenen Stellung in Gustavo Adolfo Bécquers Spatzenbuch verlangt. 
Das Gedicht betont schreibend die Unmöglichkeit, etwas zu schreiben, betont sprechend die Unmöglichkeit, zur Geliebten sprechend dieser das nicht Mitteilbare mitzuteilen. Und so wird die nicht gegebene Kommunizierbarkeit in eine intime Kommunikation verwandelt, welche nur im Gedicht, nur in der Verdichtung, nur in der Fiktion möglich wird. Dieser Topos der Unsagbarkeit, der innerhalb der Tradition klassischer Rhetorik natürlich tief in die Antike zurückreicht, ist bei Bécquer sehr häufig zu finden. Aus dieser Kluft zwischen Unsagbarem und Sagen-Müssen heraus sind viele der Gedichte aus der Feder des spanischen Spätromantikers geschrieben.

Zweifellos erzeugt das Gedicht dadurch eine Spannung, da das lyrische Ich immerhin von sich behauptet, von einer solch gigantischen und fremdartigen seltsamen Hymne zu wissen und diese geradezu göttliche Musik in Worte umsetzen zu können. Damit sind die synästhetischen Dimensionen seiner Dichtung, aber auch dieses Gedichts angesprochen, in dem sich Farben und Noten, aber auch das Leben selbst mit seiner Ambivalenz von Seufzern und Lachen, von Liebestrunkenheit und Todessehnsucht präsentieren kann. Wie später bei Arthur Rimbaud erscheinen Töne als Farben, aber auch Klänge als Bilder. Das Gedicht enthält in der Tat die Fortsetzung der Poetik von Bécquers sogenannter „symphonischen Einführung“: Alles ist sinnreich orchestriert.

Das Thema des Ungenügens der eigenen Sprache macht nicht zuletzt aber auch darauf aufmerksam, dass sich jenseits der Sprache, die der Dichter benutzt und das Publikum lesen kann, noch eine andere Sprache verbirgt, die seltsam und fast unzugänglich, im eigentlichen Sinne fremd und außerhalbbefindlich („extraño“) ist. In dieser anderen Sprache sind wir weit entfernt von jenem Idiom, das sich der Dichtkunst gegenüber als rebellisch und gemein (,mezquino“) erweist. Diese andere Sprache, die gleichsam anagrammatisch als Wörter unter den Wörtern des Gedichts liegt, soll im Gedicht selbst evoziert werden oder besser noch - bedeutungsreich anklingen. Das lyrische Ich entwirft ein Bild dieser Sprache, die in der gemeinen Sprache versteckt ist und vom Dichter befreit werden muss.

In diesem Zusammenhang ist erneut die Lichtmetaphorik von großer Bedeutung, insoweit die Nacht der Seele von einem möglichen Lichtschein durch den Hymnus erhellt werden kann. Die Wendung „estas páginas“verweist darauf, dass sich dieses Gedicht sehr wohl als Sprachrohr des gesamten Bandes sieht, also eine Einheit auf kotextueller Basis herzstellen und zu präsentieren versucht. Das prekäre Transportsystem und mediale Mittel der Übermittlung ist dabei die Luft und damit auch die musikalische Dimension der Lyrik, die von allem Anfang an in ihr enthalten ist. Paul Verlaines „De la musique avant toute chose“ ist in diesen Elfsilbern und Dreizehnsilbern, in diesem polyrhythmischen Gedicht also von Anfang an zugegen. 
Die inhaltliche Argumentationsstruktur ist von den Versanfängen bereits vorgegeben: Dem zweimaligen „Yo“ zu Beginn von Strophe 1 und Strophe 2 steht ein „Pero“ entgegen, das erst zur letzten Bewegung und Bewegtheit der direkten Ansprache an die schöne Frau im Gedicht führen und damit den Liebeszyklus, den Liebesreigen eröffnen wird. Eine Beherrschung der rebellischen, widerspenstigen Sprache durch den Menschen und mehr noch durch den Mann („hombre“) ist nicht vollständig gegeben, denn dem Willen des Individuums beugt sich die (dichterische) Sprache nicht so leicht. Dabei sollten Worte entstehen, die zugleich Seufzer und Lachen, Farben und Klänge sind, die also in der Unmittelbarkeit das Auseinandergetretene der Empfindungen und Sinneseindrücke gleichsam synthetisierend zusammenführen und verdichten. Lyrik ist in diesem Umfeld ein Prozess des Ambivalent-Machens und zugleich einer Verdichtung und Verschmelzung des in der Sprache wie in der lebensweltlichen Erfahrung eigentlich voneinander Getrennten. Genau damit ist Lyrik freilich noch immer jene schöpferische Erfahrungsmöglichkeit, die sich jenseits des analytischen Verstandes und seiner rationalen Logik bietet; denn Dichtung ist viellogisch.

Doch sei der Kampf vergeblich, so heißt es in der dritten Strophe, da es keinen Schlüssel und mehr noch keine Chiffre und damit ein zugängliches Geheimwissen gibt, an das alles angeschlossen werden könnte und an dem alle, Dichter wie Leser, gemeinsam partizipieren. Danach erfolgt die Einschränkung auf eine Beziehung zwischen einem Ich und einem Du, zwischen einem Mann und einer Frau, die beide unmittelbar über ihre Körperlichkeit zusammengeführt werden, indem die ,Schöne‘ ihre Hände in die seinen legt. In dieser Beziehung erscheint noch so etwas wie ein letzter Funke jener ,aurora“, die der Gedichtanfang versprach. Die Anrufung an die „hermosa“ erfolgt überraschend kurz vor Ende des Gedichts, gibt allem aber vom Ausklang her seinen Sinn in der Engführung von Lyrik, Sprache und Liebe. Dergestalt erfüllt dieses Gedicht seine Eröffnungsfunktion gegenüber dem gesamten Gedichtband.

Denn die Kommunikation wird nun im Bereich der Mündlichkeit möglich. Was das Gedicht also erzählt, ist die Unmöglichkeit einer schriftlichen Kommunikation auf diesen Seiten, welche ihren letzten Ausweg in der Mündlichkeit des Erzählens zu finden scheinen. Diese Mündlichkeit wird mit Hilfe der Lyra der Musik in einen Hymnus verwandelt, der in seiner ganzen gigantischen Kraft erstrahlt und das Gedicht selbst vermittels der Lexem-Rekurrenz bezeichnet. Die mündliche und körperliche, also doppelt unmittelbare Kommunikationssituation wird in eine schriftliche und damit auch künstlerisch bearbeitete Kommunikationssituation überführt, welche Kunst und Liebe zusammenbringt. Die Liebe also bildet jene letzte, erhoffte Möglichkeit einer unmittelbaren, unvermittelten Kommunikation, die im Gedicht nur noch mittelbar, dafür aber mit den Mitteln der Kunst, jene andere Sprache hinter der Sprache sichtbar und mehr noch hörbar 
werden lässt, welche außerhalbbefindlich und zugleich gigantisch, großartig, außerordentlich ist. Auf diese kunstvolle Weise sind die Gedichte Gustavo Adolfo Bécquers immer zugleich auch Gesänge: Lieder - von der deutschen Liedkunst der Romantik war er stets besonders geprägt - und damit hymnische Musik.

Lassen Sie uns an dieser Stelle zum Abschluss noch ein zweites kurzes Gedicht aus der Sammlung der Rimas analysieren! Es ist in meiner, dem Original des Spatzenbuches folgenden Ausgabe das zwölfte, in anderen das fünfzigste Gedicht. Gerade aus der Perspektive unserer Vorlesung scheint es mir von besonderer Bedeutung zu sein:

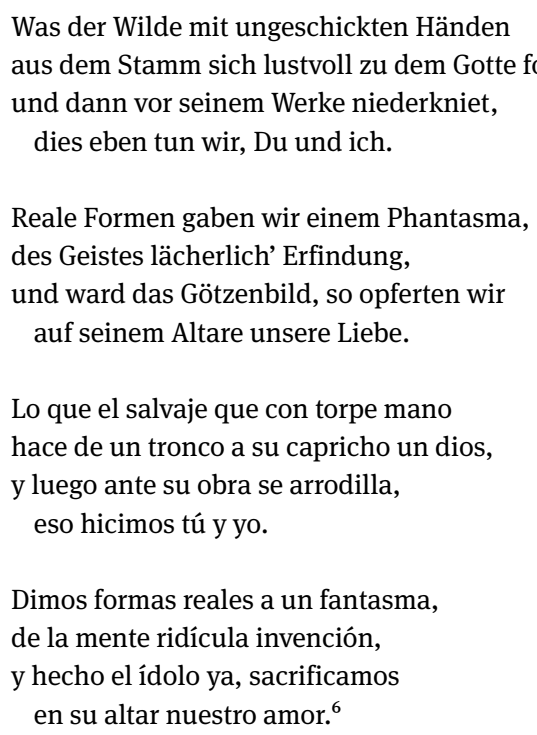

Auch dieses polymetrische zweistrophige Gedicht ist in seiner Formensprache wiederum sehr an jener „sencillez“, an jener Einfachheit ausgerichtet, deretwegen Gustavo Adolfo Bécquer sicherlich auch als Vertreter einer neuen Moderne gefeiert werden konnte. Es lassen sich zweifellos bereits Anklänge an Gedichte des Modernismo konstatieren, etwa zu José Martís Gedicht Crin hirsuta. Als eher konservativ ist die Tatsache einzuschätzen, dass wiederum Satz- und Strophengrenzen übereinstimmen. Wie Martí in seinen berühmten Versos sencillos, von denen Sie sicherlich in Liedform Guantanamera kennen, verabschiedet schon Bécquer allen romantischen Pomp und schreibt sich bewusst in jene volkssprachliche Dichtungstradition ein, welche in Spanien mit seinen zahlreichen

6 Bécquer, Gustavo Adolfo: Rimas; Leyendas escogidas, S. 104. 
populären Sprichwörtern und Volksweisen stets eine Unterströmung aller Lyrik darstellt.

Aufschlussreich ist freilich, dass dieses Gedicht eine spannungsvolle Beziehung zwischen der Kunst europäischen, ,zivilisierten‘ Zuschnitts und der Kunst des „salvaje“, eines ,Wilden“, herstellt. Der ,Wilde“ ist im Spanischen etymologisch vom lateinischen „selvaticus“ abgeleitet, der sozusagen dem Wald verpflichtet ist und auch in selbigem wohnt. Daher bearbeitet er auch das, was ihm am nächsten liegt, einen Baumstamm also, was die Unmittelbarkeit eines wilden Denkens (im Sinne von Claude Lévi-Strauss ${ }^{7}$ ) und einer wilden Kunst unterstreicht, die religiös verankert ist und vom lyrischen Ich als götzenhafte Anbetung gedeutet wird. Mit diesen Formulierungen wird natürlich auf die Dimension der Kunstverfertigung und der Schaffung von Kunst- und Kultobjekten angespielt, also nicht nur die tiefe Beziehung der Kunst (und gerade der abendländischen Kunst) zum Ritus und mehr noch zum Cultus herausgestellt, sondern auch auf einen Mythos angespielt, der hier ungenannt bleibt. Es handelt sich um den uns aus Honoré de Balzacs Novelle Sarrasine vertrauten Pygmalion-Mythos, in welchem sich der Künstler in sein eigenes Werk verliebt und diese Schöpfung seiner selbst vergöttert, sie mit anderen Worten zu seinem Idol und Götzenbild werden lässt. Damit ist die Beziehung zwischen Künstler und Kunstwerk selbst thematisiert, nicht nur die Problematik einer ,wilden' Kunst als Kunst in einem kulturellen Kontext, der nicht jener der abendländisch-christlichen Zivilisation ist. Es geht um die Beziehung zwischen dem Schöpfer und seiner Schöpfung.

Wie im vorigen Gedicht tritt auch in diesem das Element der Liebe - und damit des Übergangs zwischen Kunst und Leben - hinzu. Erneut wird zwischen $\mathrm{Du}$ und Ich eine Liebessituation entfaltet, in welcher Lieben, Leben und Kunst miteinander verquickt sind. Die ungeschickte, nicht künstlerisch gebildete Hand des Wilden verfertigt im Grunde nichts anderes als das, was die ungeschickten Liebenden tun, die sozusagen zusätzliche Dimensionen einer wahren Kunst auslassen und einfach überspringen. Sie tun dies, indem sie ihre eigene Schöpfung, ihre eigene Liebe, die sie beide zusammen hervorgebracht haben, zum Gegenstand eines eigenen Kultes, zum Kultobjekt also fetischisiert haben. Das Abstractum der Liebe wird dabei auf dem Altar ihrer Verfestigung einer realen objektiven Form geopfert: Die Liebe als Form hat die Liebe als Idee hinter sich gelassen.

7 Vgl. hierzu Lévi-Strauss, Claude: La Pensée sauvage. Avec 11 illustrations dans le texte et 13 illustrations hors texte. Paris: Plon 1962; sowie (deres.): Das wilde Denken. Eine Diskussion mit Paul Ricoeur, Marc Gaboriau, Michel Dufrenne, Jean-Pierre Faye, Kostas Axelos, Jean Lautman, Jean cuisinier, Pierre Adot und Jean Conilh. In (ders.): Mythos und Bedeutung. fünf Radiovorträge. Frankfurt am Main: Suhkamp 1980, S. 71-112. 
Auf diese Art erweist sich der Begriff „capricho“ in der Tat als doppeldeutig, meint er doch nicht nur jene Capriccios des Bereichs jenseits der abendländischen Vernunft, der auch schon in Goyas berühmten Caprichos mitgedacht worden war, sondern zugleich auch das kapriziöse einer Liebesbeziehung, die nun von einem Gebilde der Einbildungskraft auf eine reale lebensweltliche Ebene übergegangen beziehungsweise übergesprungen ist. Gewiss, auch dies erscheint letztlich als „torpe mano“, als „capricho“, nicht aber als Kunst in einem emphatischen Sinne, wie sie die Kunst Bécquers anstrebt.

Gleichzeitig entwirft das Gedicht aber jenseits der Spannung zwischen Kunst, Künstler und Kunstwerk ein fundamentales Spannungsverhältnis zwischen Leben, Lieben und Kunst, in dem es im Grunde keine Eindeutigkeiten, keine eindeutigen Zuschreibungen gibt. Denn die Verwandlung des Phantasmas wird nicht einfach als Degradierung verstanden, ist dieses Phantasma doch im Geiste eine durchaus lächerliche Erfindung, womit der fiktionale Charakter vor der Verfertigung zum Kunstwerk angesetzt wird. Dies war bereits in der Introducción der Fall, wo die Ideen letztlich ebenfalls das Fiktionale der Einbildungskraft körperlos und nicht objekthaft verkörpern. Zugleich sind die realen Formen aber keinesfalls die Umschreibung eines erreichten Zieles, einer Erfüllung, die auch in diesem Gedicht nicht trostreich aufleuchtet.

Denn auf dem Altar des Idols, der Vergötterung und des Götzenbildes, wird die Liebe buchstäblich aufgeopfert. Die Vergötterung des Anderen und der anderen lässt also den Begriff und die Vitalität der Liebe selbst zu einem OpferGut, zu einer Opfergabe im eigentlichen Sinne verkommen. Die Umsetzung der gemeinsamen Liebe in ein Kunstwerk, in eine Fiktion der Einbildungskraft, die in reale Formen gegossen wurde, macht dieses zu einem Artefakt, das selbst die Sprache nicht zum Ausdruck zu bringen vermag. Damit ergeben sich deutliche Parallelen zum Gedicht vom Himno gigante y extraño. Denn auch dort liegt das letztlich zu Erreichende sowohl jenseits der Phantasmen der Einbildungskraft als auch jenseits der realen Formen der Liebe, aber ebenso jenseits von deren Umsetzung in ein Kunstwerk, das vom Ich und seiner ,Schönen“ in Verkennung der (selbst-)zerstörerischen Dimensionen angebetet wird: Der Pygmalion-Mythos schimmert durch.

Es ist wohl erst das Gedicht selbst, das zu alledem gleichsam die Metaebene liefert. Es eröffnet im besten Sinne einen Zugang zu dieser anderen Welt, wenn auch nicht die Erfüllung. Die von Pygmalion geschaffene objektive, objekthafte Struktur, das von ihm geschaffene Kunstwerk, die von ihm zum Leben erweckte künstlerische Form der angebeteten Frau führt nicht zur Erfüllung. Insoweit steht eine ,wilde“ Kunst, die gewöhnlich als das ,Andere‘ der abendländischen Kunst erscheint, für keine grundlegend anderen Maßstäbe als eine Kunst, die allzu sehr nach den „formas reales“ schielt und darüber die Unerreichbarkeit der schöpfe- 
rischen Essenz und der Liebe vergisst. Pygmalion ist auf beiden Seiten der Kunstverfertigung gegenwärtig.

Damit gewinnt Gustavo Adolfo Bécquer aus der Konfrontation mit dem Wilden, mit dem ,wilden' Denken der Selbstbezüglichkeit, der Autoreflexivität aller Kunst in diesem Gedicht eine neue Seite ab. Denn eben mit diesem „salvaje“ wird die Liebe zwischen Ich und $\mathrm{Du}$ in eine identifikatorische Beziehung überführt. Sie sehen, wie in diesem auf den ersten Blick so unscheinbaren zweistrophigen Gedicht mit seinen Wechseln von Elfsilbern und Achtsilbern eine Poetik entfaltet wird, die letztlich das Rätsel der Kunst überhaupt aus einer Konfrontation von abendländischer und nicht-abendländischer Kultur zu beleuchten versucht, aus einer Konfrontation von ,Zivilisation' und ,Barbarei', die sich nur scheinbar in völliger Opposition gegenüberstehen. Ist dies bereits eine Öffnung gegenüber nicht-abendländischen Kunstformen, speziell etwa - wie in der avantgardistischen europäischen Kunst der historischen Avantgarden - gegenüber der Kunst und den Kunstformen Afrikas?

Ich glaube nicht. Doch liefert mir dies das Stichwort, um damit ein weiteres Mal den Atlantik zu queren und zu einer Thematik vorzustoßen, die erneut aus der Gegenüberstellung von spanischsprachiger Karibik und argentinischem Cono Sur vor allem den letztgenannten, in dieser Vorlesung wiederholt behandelten Raum prägte. Sie sollte ihn in veränderter Form auch bis weit ins 20. Jahrhundert hinein strukturieren: Es geht einmal mehr um das kulturelle Spannungsverhältniszwischen „Civilización y Barbarie“.

Gehen wir damit ein letztes Mal in die Zeit um die Mitte des 19. Jahrhunderts zurück und beschäftigen wir uns mit jenem Dichter, der auf der Insel Kuba als der einzige wirklich populäre Dichter, so Ambrosio Fornet, ${ }^{8}$ gelten darf; Gabriel de la Concepción Valdés oder, wie ihn die Literaturgeschichten, aber auch schon sein zeitgenössisches Publikum kannten und nannten: Plácido!

Für die überragende Bedeutung von Plácido spricht auch die Tatsache, dass wir diesen im Jahre 1844 erschossenen Dichter im Grunde bereits kennengelernt haben, lehnt sich doch Gertrudis Gómez de Avellanedas Titelgestalt Sab deutlich an bestimmte biographische Züge des jungen Dichters an. Denn Plácido ist Mulatte, und allein dies ist in seiner Außergewöhnlichkeit signifikant für einen literarischen Prozess, der wohl in Kuba, in dieser Stärke aber nicht in anderen literarischen Areas und Regionen der hispanoamerikanischen Welt beobachtbar ist. Mit Gabriel de la Concepción Valdés wird das Objekt von Literatur, der wohlgeformte Mulatte, endgültig zum Subjekt der Literatur: Er avanciert zum Schrift-

8 Vgl. Fornet, Ambrosio: Literatura y mercado en la Cuba colonial (1830-1860). In: Casa de las Américas (La Habana) 84 (1974), S. 40-52. 
steller, der ein breites Publikum erreicht und in die Literaturgeschichten Einzug hält.

Ich setze mich daher bewusst dem Vorwurf aus, mich in meiner Vorlesung ein wenig zu stark der kubanischen Seite zuzuwenden, und bleibe noch eine kurze Weile auf der Insel, die stets a contratiempo, im Gegenrhythmus zu anderen Areas der spanischsprachigen Welt Lateinamerikas funktioniert. Denn Kuba ist historisch und politisch über das gesamte 19. Jahrhundert hinweg noch immer eine Kolonie, entwickelt aber eine Nationalliteratur, die anderen existierenden Staaten Lateinamerikas an Größe und Stärke zumindest ebenbürtig ist und Entwicklungen antreibt, welche in anderen Areas noch Jahrzehnte länger auf sich warten lassen. Im 20. Jahrhundert wurde Kuba dann mit der Kubanischen Revolution von 1959 in deren eigener Diktion das „Primer territorio libre de América“ und schlug einen politischen und gesellschaftlichen Weg ein, auf dem der Insel kein weiteres Land Lateinamerikas folgte. Selbst nach dem Ende der Sowjetunion und trotz aller politisch-militärischen Versuche, die Insel einzuschnüren und vom Welthandel abzukoppeln, hat sich Kuba nicht von diesem Weg abbringen lassen und behauptet seine Position in der Globalgeschichte a contratiempo.

Mit Plácido wird der Mulatte, wird der Schwarze, wird der ehemalige Sklave zum schreibenden Subjekt, das über die Gesellschaft reflektiert und sich nicht länger damit zufrieden gibt, willfähriges oder rebellisches Objekt einer kolonialen Sklavenhaltergesellschaft zu sein. Nicht weniger bedeutsam ist die Tatsache, dass Gabriel de la Concepción Valdés eines gewaltsamen Todes sterben musste, ungerechterweise von den kolonialspanischen Behörden angeklagt, an der Conspiración de la Escalera teilgenommen zu haben. Diese sogenannte „Konspiration“ war ein planvoll aufgebautes Hirngespinst der kolonialspanischen Administration, mit deren Hilfe man missliebige Bewegungen bekämpfen und unterdrücken konnte, so dass man den Dichter zusammen mit anderen, die man zur Warnung für aufmüpfige Geister festnahm, standrechtlich erschießen konnte.

Diese historische Szenerie hat sich tief in das kubanische Kollektivgedächtnis eingebrannt, wurde entscheidend für alle späteren Aufstände, Rebellionen und Revolutionen und für den kubanischen Nationenbildungsprozess. Innerhalb der kubanischen Literatur wurde die Conspiración de la Escalera mehrfach aufgearbeitet und gestaltet; auf besonders kreative Art und Weise etwa auch von Guillermo Cabrera Infante in seinem Vista del amanecer en el Trópico. Das seit mehr als einem halben Jahrhundert wieder erneuerte Interesse an Plácido kommt übrigens nicht von ungefähr, ist doch seine „Mulatez“ innerhalb eines Staates, der sich offiziell auf diese mulattische Herkunft bezieht, von großer politischer, sozialer und ethnischer Wichtigkeit. Vielleicht aber sollten wir uns zunächst einige Biographeme dieses weithin bis heute unterschätzten kubanischen Dichters näher anschauen. 
Gabriel de la Concepción Valdés alias Plácido wurde am 18. März 1809 in Havanna geboren und starb am 28. Juni 1844 in Matanzas. Er war der uneheliche Sohn einer spanischen Tänzerin und eines mulattischen Friseurs und damit das, was man heute als einen Afrokubaner bezeichnet. Um die Affäre zu verheimlichen, wurde er in ein öffentliches Waisenheim gebracht, aus dem ihn sein Vater zu sich holte. Auf den Namen Valdés waren wir beim Roman Cecilia Valdés von Cirilo Villaverde bereits gestoßen: Auch die Heldin dieses großen kubanischen Romans des 19. Jahrhunderts erhielt ihren Namen im kubanischen Waisenhaus und wuchs als uneheliche Tochter in La Habana auf. In der großen kolonialspanischen Stadt der Karibik hätten sich die beiden Waisenkinder zweifellos begegnen können.

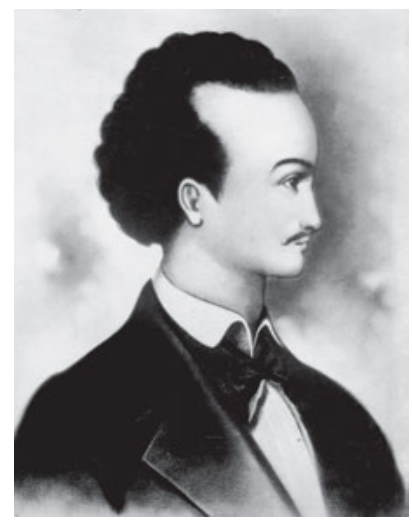

Abb. 66: Diego Gabriel de la Concepción Valdés (La Habana, 1809 - ebenda, 1844).

Der spätere Plácido besuchte eine Armenschule in Havanna, war jedoch ab 1821 gezwungen, sein Überleben zu sichern und zu arbeiten. Bildung und Ausbildung des jungen Mulatten standen folglich nicht im Zeichen großer Kontinuität. Nacheinander war er Tischler, Schriftsetzer, Kammmacher und Silberschmied; in der Werkstatt von Vicente Escobar lernte er das Zeichnen und Grundlagen der Kalligraphie. Bereits ab 1823 zeigte er bei seiner Schriftsetzer-Lehre großes dichterisches Talent, das er jedoch angesichts der Zwänge des Geldverdienens zurückstellen musste. Ab 1836 wurde er zugleich Redakteur der Zeitung La Aurora von Matanzas und vermochte in dieser nicht weit von Havanna gelegenen Küstenstadt erstmals durch sein Schreiben auf sich aufmerksam zu machen.

In Gabriel de la Concepción Valdés' Leben fehlt es nicht an tragischen Akzenten. 1832 hatte er sich in die schöne Fela verliebt, eine freie Schwarze, die jedoch im Folgejahr im Zuge der Choleraepidemie in Havanna verstarb. Seine finanziellen Schwierigkeiten begleiten ihn bei seinen Tätigkeiten für eine Reihe von Zeitungen und Zeitschriften. Auf Grund von Zahlungsschwierigkeiten wandert er mitunter 
ins Gefängnis, wobei das rassistische Rechtssystem nicht viel Federlesens mit einem Mulatten machte. Sein Schreiben, seine häufigen Ortswechsel und die Kontakte mit Personen aus allen Gesellschaftsschichten erweckten den Verdacht der spanischen Kolonialbehörden, die dem Aufstieg der ,freien Schwarzen‘ ein Ende bereiten wollten. Kurz nach seiner Heirat mit María Gila Morales y Póveda wurde er im Jahr 1842 auf der Suche nach Arbeit in der noch heute wunderschönen kubanischen Stadt Trinidad festgenommen und blieb sechs Monate unbegründet und ohne Anklage im Gefängnis. Er kehrte wieder nach Matanzas zurück, wo er erneut verhaftet und - ohne jeden Beweis - wegen Teilnahme an der erwähnten Conspiración de la Escalera zum Tode verurteilt wurde. Gemeinsam mit weiteren zehn Angeklagten wurde er im Alter von fünfunddreißig Jahren in Matanzas füsiliert.

Es waren die literarischen Tertulias von Matanzas, insbesondere die von Ignacio Valdés Machuca, die für Plácidos lyrische Entwicklung wichtig wurden. In der Forschungsliteratur wurde ihm oft nachgesagt, dass er nur ein besserer Handwerker gewesen sei und dass er seine Gedichte ähnlich wie seine ,peinetas de carey“ oder seine Arbeiten als Silberschmied für den raschen Gebrauch verfertigt habe. Dies scheint mir freilich ein impliziter Rassismus zu sein, der nur den populären Charakter seiner Lyrik anerkennt, nicht aber die große Bedeutung seines Schreibens für die kubanische Nationalliteratur.

Das umfangreiche lyrische Werk des unglücklichen Dichters zeugt von einer außerordentlichen dichterischen Begabung. Gewiss war Plácido darauf angewiesen, durch mancherlei Gelegenheitsgedichte auf sich aufmerksam zu machen und auch Geld und Ansehen zu verdienen. Doch bei allem Traditionsbewusstsein entfaltete der Kubaner eine neue Sprache, welche in ihrer Musikalität und Rhythmik sehr eigene Wege beschritt. Sicherlich klagte Plácido selbst darüber, dass er für Feierlichkeiten oder Geburtstage der kubanischen Aristokratie sein dichterisches Talent verschwenden müsse, doch verstand er sich ausgezeichnet darauf, die Traditionen spanischer Dichtung mit dem Rückgriff auf lyrische Formen des kubanischen Volkes in einer romantischen Lyrik zu verbinden, welche den Hang der Romantik zum zuvor verdrängten Traditionsreichtum populärer Kultur zum Ausdruck brachte.

Überdies gelang es dem kubanischen Dichter, in seine Auftragsarbeiten zur Lobpreisung etwa der spanischen Herrschaft deutlich rebellische Aussagen einzustreuen, die in den dreißiger Jahren noch durchgingen. Immer wieder taucht das Thema Tyrannei auf, die freilich fernab der Karibik in exotische Landstriche verlegt wird. Wie Gertrudis Gómez de Avellanedas Sab pflegt er Vorstellungen eines Indianismus, in dem deutliche Kritik am herrschenden kolonialspanischen Regime historisch distant zum Ausdruck kommt. Vor allem aber beeindruckt die rhythmische Musikalität, mit welcher Plácido der romantischen Lyrik eine neue Gangart bescherte. Die noch kurz vor seiner Hinrichtung verfassten Gedichte, mit 
denen wir uns gleich beschäftigen wollen, machen die ganze lyrische Spannweite und Ausdrucksmöglichkeiten dieses in jeglicher Hinsicht außerordentlichen kubanischen Dichters deutlich.

Zwischen 1825 und 1845 gab es ohne Zweifel auf der Insel einen gewissen Boom und ein rasch gewachsenes Interesse an einer ,afrokubanischen' Literatur, zu der im Allgemeinen der vom Phänotyp her ,weiße‘ Plácido gezählt wird. Zweifellos waren es gerade die ,freien' Schwarzen und Mulatten, die für die spanischen Kolonialbehörden gefährlich werden konnten, bildeten sie doch eine gesellschaftlich stark dynamisierende Gruppe von Aufsteigern innerhalb einer sich zögernd modernisierenden kubanischen Kolonie. Ihnen vor allem galt die Erfindung einer Verschwörung, die nicht nur mit der potentiellen Gefährlichkeit der freien Schwarzen und Mulatten, sondern auch mit ihrem Schreiben, journalistischen wie künstlerischen, vor allem aber im Modebereich schöpferischen Ausdrucksformen zu tun hatte. Die Verbindungen zwischen dieser gesellschaftlichen Gruppe von freien Schwarzen mit einer abolitionistischen Literatur auf Kuba war der Kolonialverwaltung ebenfalls ein Dorn im Auge. Gewiss war Plácido trotz mehrerer entsprechender Angebote nicht ins Exil gegangen; doch bedarf es schon einer - sagen wir - ,selbstbewussten“ Ideologie, um ihn als Freiheitskämpfer darzustellen oder Fidel Castro gar zum Vollstrecker seines Denkens zu erklären. ${ }^{9}$

Gabriel de la Concepción Valdés war, wir hatten es erwähnt, der Sohn eines mulattischen Friseurs mit einer spanischen Tänzerin, eine gewiss ungewöhnliche Verbindung, da weiße Frauen sich laut des gängigen Ehrenkodex, der auch die sexuellen Beziehungen regelte, eher selten mit nicht-weißen Männern einließen. Die Spanierin brachte den Jungen in die Casa de Beneficiencia, wo er den Namen Valdés erhielt, den er nicht mehr ablegte, obwohl ihn sein Vater schon bald aus dem Waisenhaus holte. Der spätere Plácido bekannte sich zu seiner doppelt marginalisierten Lage als Kubaner und Mulatte; und eben dieses öffentliche Bekenntnis und nicht etwa revolutionäre konspirative Bestrebungen dürften die Hauptgründe dafür gewesen sein, dass man gerade diesen jungen selbstbewussten Mann als eine wortwörtlich zu verstehende Zielscheibe herausgriff und standesrechtlich ermordete. Plácido bezog sich keineswegs auf die aufrührerischen und für das kubanische Nationalbewusstsein wichtigen Gedichte seines Landsmanns Heredia, der ihn ebenfalls ins mexikanische Exil einlud; eine Einladung, die Plácido aber ausschlug, wollte er doch in Kuba bleiben.

9 Vgl. etwa Grötsch, Kurt: El destino entre esclavitud, literatura e identidad cubanas. Plácido, Martí y Morúa Delgado. In: Heydenreich, Titus (Hg.): Kuba. Geschichte - Wirtschaft - Kultur. München: Fink 1987, S. 237-278. 
Halten wir also fest: Plácido ist ein kolonial und ethnisch doppelt Marginalisierter; aus dieser Position heraus wird seine Lyrik neu lesbar! Die Abwertung des Mulatten zum geschickten,Vershandwerker' hat eine lange Tradition, der wir in kurzgefasster Form und unter Einbeziehung damaliger Klischees nachspüren wollen. In den zwanziger Jahren fiel in Matanzas auf, mit welcher Leichtigkeit dieser Gabriel de la Concepción Valdés Verse schmieden konnte. Wie viele aus seiner gesellschaftlichen Gruppe arbeitete der gepflegte junge Mann im Modebereich, stellte er doch aus Schildkrötenpanzern (Pattschildkröten) Kämme und andere modische Accessoires und Schmuckgegenstände her; eine zeitweise recht einträgliche Arbeit, die allerdings - hart ist das Modegeschäft - nur wenige Jahre Brot einbrachte.

Bald wurde für ihn auch die dichterische Seite als Einnahmequelle wichtig; so verdingte er sich, gegen billiges Geld für das Periodikum Aurora von Matanzas ein tägliches Gedicht zu liefern. Das trug Plácido selbstverständlich den Ruf eines Gelegenheitsdichters und mehr noch Handwerkers ein; ein Ruf, der sich bis heute hartnäckig hält und sein Bild noch weitgehend bestimmt. 1834 hatte er erstmals in einem literarischen Wettbewerb, den er gewann, großen Erfolg. Seit diesem Zeitpunkt weitete sich sein Ruhm rasch aus, so dass seine Verse bald zu den meistgelesenen und meistrezitierten der Insel wurden.

Zu diesem Erfolg beim Publikum gehörte es selbstverständlich auch, Gedichte zu Ehren hochgestellter Persönlichkeiten zu verfassen. Plácido kam dieser Pflicht aus nachvollziehbaren finanziellen Gründen nach, litt er doch stets unter Geldnot. Man sollte ihm daraus jedoch keinen moralisierenden und aus heutiger Sicht anachronistischen Strick drehen: Denn seine Position war nicht mit jener José María Heredias vergleichbar, der im literarischen Feld Kubas, das zum damaligen Zeitpunkt bereits zweigeteilt in Insel und Exil war, die beherrschende Figur als Dichter darstellte. Seine Gedichte zirkulierten auf der ganzen Insel; und selbst im Ausland wurden Plácidos Gedichte gelesen. Dort freilich wurde der junge Mulatte fälschlich als revolutionärer Schwarzer bezeichnet; ein Bild, das wenig mit den Tatsachen, aber viel mit der revolutionären französischen Aufklärungsliteratur etwa eines Diderot oder Raynal zu tun hatte, auf deren Einfluss im karibischen Raum wir bereits mehrfach in dieser Vorlesung stießen.

Plácidos zahlreiche Gedichte zirkulierten noch auf Kuba, als ihr Autor längst erschossen und ihre Publikation verboten worden war. Die mit Dummheit gepaarte Brutalität der spanischen Kolonialverwaltung wird auch am Beispiel der Ermordung dieses kubanischen Dichters deutlich: kein Wunder, dass Spanien als Kolonialmacht alle Sympathien einbüßte! Plácido wurde rasch zur Legende, oder mit anderen Worten: Nicht nur seine Gedichte waren populär; er selbst wurde binnen kurzer Zeit zum Teil einer Populärkultur der Karibikinsel. Es erstaunt daher nicht, dass manche Kritiker ihn später zu einem „versificador“, einem Verseschmied 
abqualifizierten und wie beispielsweise Manuel Sanguily 1894 in Abrede stellten, dass es sich bei diesem Mulatten wirklich um einen Dichter gehandelt habe.

Wir dürfen und müssen derlei Aussagen auf dem Boden der interrassischen Auseinandersetzungen und eines gesamtgesellschaftlich verbreiteten Rassismus, zugleich aber auch innerhalb des literarischen Feldes insoweit interpretieren, als Plácidos Dichtungskonzeptionen gänzlich im Gegensatz zur Poetik des ausgehenden 19. Jahrhunderts standen, in welcher schon modernistische Positionen die Oberhand gewonnen hatten. Gabriel de la Concepción Valdés war also in mehrfacher Hinsicht ein Marginalisierter und Ausgestoßener. Seine Dichtkunst, die sich an möglichst breite Schichten des Volkes wandte, tagtäglich in Zeitungen erschien und hermetischem Dichten abhold war, konnte zum damaligen Zeitpunkt nicht mehr akzeptiert und ernstgenommen werden.

Von unserer heutigen Warte aus, die unter anderem durch eine höhere Sensibilität gegenüber marginalisierten Gruppen charakterisiert ist, sind derartige Vorgänge freilich wieder auf andere Weise bewertbar geworden - ohne dass man jedoch die zeitgeschichtlichen und auf das literarische Feld Kubas in der ersten Hälfte des 19. Jahrhunderts bezogenen Aspekte aus den Augen verlieren dürfte. Plácido wurde lange Zeit nicht in den Parnass der kubanischen Lyrik aufgenommen: Auch auf dieser Ebene blieb er später, um einen Ausdruck von Wolfgang Borchert zu übernehmen, draußen vor der Tür. Es ist an der Zeit, diese Literaturgeschichtsschreibung zu korrigieren! Denn mit Plácido betritt eine soziale und ethnische Klasse und Gruppe gegen Mitte des 19. Jahrhunderts die literarische Bühne und macht sich zum Subjekt kubanischer und spanischsprachiger Dichtkunst; das ist in diesem Sinne ein revolutionärer Akt, den man nicht mit Schweigen übergehen sollte. Politische Missverständnisse und Fehldeutungen dieses mulattischen Dichters als revolutionärer Freiheitskämpfer werden der großen Gestalt des in jungen Jahren Ermordeten sicherlich nicht gerecht.

Gabriel de la Concepción Valdés bewegte sich - wie seine Zeitgenossen, zu denen José María Heredia zählte - in seiner dichterischen Entwicklung vom rhetoriklastigen Neoclasicismo seiner ersten Verse zum Romanticismo seiner späteren Kompositionen, wobei er sich nicht früh wie Heredia auf vielfach unbekanntes Terrain vorwagte, sondern romantische Formulierungen wählte, als die Romantik unverkennbar bereits Oberwasser innerhalb der hispanoamerikanischen Dichtungspraxis bekommen hatte. Dies ist angesichts seiner Randständigkeit innerhalb des literarischen Feldes Kubas nur allzu verständlich und könnte auch kaum anders sein: Es ging für ihn darum, als Mulatte überhaupt als Dichter ernst genommen zu werden.

Wir brauchen diese ästhetische Entwicklung zwischen La Siempreviva von 1834 und El hijo de la maldición an dieser Stelle nicht nachzuzeichnen, zu bekannt sind uns bereits die lyrischen Parameter des Schreibens in der ersten Hälfte des 
19. Jahrhunderts. Doch möchte ich Ihnen eines seiner bekanntesten Gedichte, die 1843 - also nur kurze Zeit vor seiner Gefangennahme im Januar 1844 - verfasste und damals sehr verbreitete Plegaria a Dios in voller Länge vorstellen, um daran einige für unsere Fragestellung wichtige Aspekte aufzuzeigen:

Unermesslicher Güte Wesen, oh allmächt'ger Gott, zu Euch wend' ich mich in meinem schlimmen Schmerz; streckt Euren mächt'gen Arm hier an mein Herz, zerreißt so der Verleumdung Schleier und Spott und nehmt dies schrecklich' Mal von mir nun fort, mit dem die Welt besudelt meiner Stirne Schmerz.

König unter Königen, Gott meiner Großväter, Ihr allein seid mein einz'ger Anwalt, oh Gott mein: Alles vermag, wer des Meeres dunklen Schein die Wellen und die Fische gab, Licht den Himmeln hier, Feuer der Sonne, Wind der Luft, dem Norden eis'ge Zier, den Palmen Leben, dem Flusse Bewegung und Stein.

Alles vermögt Ihr, und alles vergehet oder gesundet in Eurer heil'gen Stimme Klang; von Euch entfernt, oh Herr, ist alles nichts und bang, das in der unergründlich Ewigkeit zergehet, und selbst dies Nichts nach Eurem Willen gehet, denn ihm allein folgt die Menschheit schon lang.

Täuschen kann ich Euch nicht, Gott der Barmherzigkeit, und Eurer ewigen Weisheit Schluss sieht durch meinen Körper auch der Seele Kuss als wär alles Luft, helle Durchsichtigkeit, Gebt Kraft, dass meiner Unschuld Ehrlichkeit der frevelnden Verleumdung widerstehen muss.

Und wenn es eurer göttlich Allmacht doch gefällt, dass ich vergehe, gleich dem frevelnden Diebe, dass die Menschen meinem kalten Leib noch Hiebe geben, boshaft Gefallen in die Höhe schnellt, dann töne Deine Stimme, end' mein Sein in dieser Welt; an mir geschehe, Gott, Dein Wille, Deine Liebe. ${ }^{10}$

10 Plácido: Poesías de Plácido (Gabriel de la Concepción Valdés). New York: Roe Lockwood \& Son, Librería Americana y Estranjera 1855, S. 450 f. 
Ser de inmensa bondad, Dios poderoso,
a vos acudo en mi dolor vehemente;
extended vuestro brazo omnipotente,
rasgad de la calumnia el velo odioso
y arrancad este sello ignominioso
con que el mundo manchar quiere mi frente.

Rey de los reyes, Dios de mis abuelos, vos solo sois mi defensor, Dios mío: todo lo puede quien al mar sombrío olas y peces dio, luz a los cielos, fuego al sol, giro al aire, al Norte hielos, vida a las plantas, movimiento al río.

Todo lo podéis vos, todo fenece o se reanima a vuestra voz sagrada; fuera de vos, Señor, el todo es nada que en la insondable eternidad perece, y aun esa misma nada os obedece pues de ella fue la humanidad creada.

Yo no os puedo engañar, Dios de clemencia;

y pues vuestra eternal sabiduría ve al través de mi cuerpo el alma mía cual del aire a la clara transparencia, estorbad que humillada la inocencia bata sus palmas la calumnia impía.

Mas si cuadra a tu suma omnipotencia que yo parezca cual malvado impío, y que los hombres mi cadáver frío ultrajen con maligna complacencia, suene tu voz y acabe mi existencia; cúmplase en mí tu voluntad, Dios mío.

Zunächst einmal ist die Tatsache unbestreitbar, wie sehr dieses Gedicht noch neoklassizistische Topoi in Umlauf setzt, blicken wir etwa allein auf jene Elemente, die der allmächtige Schöpfergott in seiner Allmacht in Bewegung gesetzt hat und die uns das lyrische Ich in seinen Strophen in Erinnerung ruft. Nicht ganz verzichten kann ich auf die Bemerkung, dass es keineswegs zufällig die See ist, welche in diesen Strophen an erster Stelle genannt wird, ist es doch gerade dieses dunkle Meer, das die Insel umgibt, auf der wenig später sich der Wille Gottes an dem jungen Dichter vollziehen - man könnte auch sagen: vollstrecken - wird. Denn Gabriel de la Concepción Valdés hat seine Plegaria im Bewusstsein seiner drohenden Hinrichtung geschrieben, seiner auf Verleumdungen zurückgehenden Erschießung. 
Doch ist es nicht in erster Linie diese tragische Dimension des Gedichts, die ich Ihnen in der Folge kurz aufzeigen möchte. Es geht mir vielmehr um die unleugbare spezifische Sensibilität Plácidos für Rhythmik und vor allem Klang, die in diesem De profundis zum dichterischen Ausdruck kommen. Denn in der lyrischen Anrede an einen Demiurgen und Schöpfergott, die von einer zweiten Person Plural am Ende in eine zweite Person Singular wechselt, stoßen wir auf eine besondere Musikalität des Dichters, welche in der Tat aufhorchen lässt.

Bereits in den ersten beiden Versen wird die Dominanz des Vokals „o“ angeschlagen, wird „Dios“ und „dolor“, werden „poderoso“ und „vos“ eingeführt, die wie mit einem Grundklang, in einem Basso continuo, das Gedicht an den „Dios omnipotente“ begleiten werden. In der Wendung „este sello ignominioso“ wird dieser Grundklang mit jener Markierung verbunden, welche die Stirn des lyrischen Ich beschmutzend und mit allerlei Verleumdungen disqualifizierend bedeckt, aufgebracht von jenen Zeitgenossen, die ohne jeden Grund Verschwörungsideologien entwickelten, um den jungen Dichter damit letztlich als möglicherweise gefährlichen Geist aus dem Weg zu räumen und in den Tod zu treiben. Das Schandmal stammt aus jener Welt, die Gottvater selbst geschaffen hat, und damit von jenen Mitmenschen, die es an jeglicher Mitmenschlichkeit in radikaler Weise fehlen lassen. Und wie gefährlich Verschwörungsideologien sind - denn es sind Ideologien und ganz gewiss keine Theorien, die als solche überprüfbar und nachprüfbar sein müssten -, kann man auch in unserer Zeit schrecklich eindrucksvoll erleben. Die ganze Conspiración de la Escalera war eine einzige Fiktion, eine reine Erfindung, die sich in absichtsvoll blutige Realität verwandelte.

Die unmittelbar darauffolgende zweite Strophe stellt den angerufenen Gott zugleich über die Könige; ein Hinweis, den wir sehr wohl mit der kolonialspanischen Herrschaft in Verbindung bringen dürfen und der gegen die Abstammung Gottes als Gott meiner Großväter spannungsvoll aufgeführt wird. Dass es gerade die Großväter sind, kann als bedeutungsvoll gelten, nicht nur, weil sich später - in den historischen Avantgarden - der kubanische Nationaldichter Nicolás Guillén in Gedichtform an seine beiden Vorfahren als Dos abuelos wandte und damit als mulattischer Poet an seinen weißen wie an seinen schwarzen Großvater erinnerte. Es macht zugleich deutlich, dass sich die Wendung nicht nur an einen Christengott richtet, sondern an Gestalten aller Religionen, stammten sie aus Europa oder aus Afrika. Wir können an dieser Stelle bereits erkennen, wie klug und geschickt Plácido seine mulattische Herkunft in seinem Gedicht zugleich ansprach und verbarg.

Das klangliche Spektrum wird im Grunde erst in der dritten Strophe - und damit genau im Zentrum, im Herzstück des Gedichts - zusammengeführt. Denn dort bemerken wir die Abfolge von „o“, von „e“ und von „,a“ wiederholt in Vokaldoppelungen oder gar Verdreifachungen. Beispiele hierfür sind etwa „todo“, 
„fenece“, „sagrada“ oder „perece“, wobei diese klanglichen Oppositionen auch inhaltlich gegeneinander geführt, zugleich aber auch ineinander geblendet werden: „el todo es nada.“ Die Überführung des Alles in ein Nichts ist nicht nur lyrischer Topos christlich-abendländischer Provenienz, sondern zugleich auch die Überführung des „O“ der Macht („todopoderoso“) in das geradezu heilige Nichts des Vokals „a“ (,sagrada“). Das Nichts ist göttlich, da es in sich auch die Schöpfung umschließt, auch die „humanidad“, welche eine göttliche Antwort auf das „nada“ beinhaltet. Die Semantik des Gedichts spielt sich gleichsam auf der phonotextuellen Ebene ab und gibt der Leserschaft sinnlich zu verstehen, welche semantischen Gegensätze und Übergänge zwischen Macht und Ohnmacht, zwischen Leben und Tod diese Schöpfung beherrschen.

Dem Vokal „e“ kommt ein gewisser Übergangsstatus zwischen „a“ und „o“, zwischen „nada“ und „todopoderoso“, zwischen „sagrada“ und „omnipotente“ zu. Dabei wird zugleich dem Tödlichen ein vokalischer Ort zugeschrieben, wie Vokal-Verdreifachungen deutlich machen: „fenece“, „perece“. So fügt sich das lyrische Ich in sein tödliches Schicksal („e“) und fühlt sich somit der Gewalt Gottes („,“) im zweitletzten Vers des Gedichts vereint: „,suene tu voz y acabe mi existencia." Hier ist nochmals das gesamte Vokalspektrum vorhanden; und doch weiß der aufmerksame Leser, die aufmerksame Leserin, dass sich gerade hinter der „existencia“ der tödliche Klang verbirgt.

Das durchdachte Spiel mit Klängen und insbesondere Vokalen, aber auch mit Rhythmen wird ein wichtiges Element afrokubanischer wie afrokaribischer Lyrik, des „Sóngoro cosongo“ der ersten Hälfte des 20. Jahrhunderts sein. Daher kommt es nicht von ungefähr, dass Plácido gerade auch von den afrokubanischen Lyrikern und ihren Theoretikern wieder aufgewertet und in seiner Bedeutung als kreativer Vorläufer dieser Lyrik erkannt worden ist. Solche literarischen Vorläufer werden, wie schon Jorge Luis Borges erkannte, immer von den Nachfolgern erschaffen; und so rückte Gabriel de la Concepción Valdés in eine Traditionslinie ein, welche es zu seinem Zeitpunkt noch nicht als solche gab und die weit ins 20. Jahrhundert und in unsere Gegenwart reicht. Es ist daher schlechterdings nicht möglich, einen solchen Dichter und damit auch eine derartige Traditionslinie aus unserer Vorlesung wegzulassen und auf Plácido als einen der großen Dichter der spanischsprachigen Romantik zu verzichten. Denn mit seiner Sensibilität für eine neue Klangwelt und Rhythmik stand er früh für jene Entwicklung ein, die erst im 20. Jahrhundert in der afrokaribischen wie in der afro-US-amerikanischen Dichtkunst reiche Früchte trug.

Gerne will ich Ihnen auch hier zur Verdeutlichung ein Gedicht aus dem zwanzigsten Jahrhundert einblenden, und zwar von dem bereits erwähnten Nicolás Guillén; aber nicht sein Gedicht Dos abuelos, das hier ebenfalls am Platze wäre, sondern einen „Son“ für Antillenkinder und damit die gesamte karibische Area, 
innerhalb derer wir uns bewegen. Sie merken: Wir sind wieder mit dem karibischen Element par excellence, dem Meer, in Kontakt und machen eine erneute Kreuzfahrt durch die karibische See der Literatur!

\author{
Auf dem Meere der Antillen \\ fährt ein Schiffchen aus Papier: \\ fährt und fährt das Schiffchen Schiffchen \\ ohne Steuer hier.
}

Von Havanna nach Portobelo, von Jamaica nach Port of Spain fährt und fährt das Schiffchen Schiffchen ohne Kapitän.

Eine Negerin geht nach achtern, und ein Spanier geht zum Bug: fährt und fährt das Schiffchen Schiffchen beide wie im Flug.

Schwimmen Inseln viel vorüber, Inseln, Inseln, immer mehr; fährt und fährt das Schiffchen Schiffchen ohne Rast umher.

Ein Geschütz aus Schokolade schoß aufs Schiffchen ab, die Kanon' aus Zucker Zucker ihm die Antwort gab.

O du mein Matrosenschiffchen, aus Papier dein Schiffsrumpf ist! $O$ mein schwarzes weißes Schiffchen ohne Maschinist!

Droben stehen das schwarze Mädchen nah dem Spanier nah, an Bord; ach, es fährt das Schiffchen Schiffchen mit den beiden fort. ${ }^{11}$

11 Guillén, Nicolás: Gedichte. Spanisch und Deutsch. Übersetzt von Erich Arendt. Auswahl und Nachwort von Dieter Reichardt. Frankfurt am Main: Suhrkamp 1982, S. 76-79. 


\begin{abstract}
Por el Mar de las Antillas anda un barco de papel: anda y anda el barco barco, sin timonel.

De La Habana a Portobelo, de Jamaica a Trinidad, anda y anda el barco barco, sin capitán.
\end{abstract}

Una negra va en la popa, va en la proa un español: anda y anda el barco barco, sin descansar.

Pasan islas, islas, islas, muchas islas, siempre más; anda y anda el barco barco, sin descansar.

Un cañón de chocolate contra el barco disparó, y un cañón de azúcar, zúcar, le contestó.

¡Ay, mi barco marinero, con su casco de papel! ¡Ay, mi barco negro y blanco sin timonel!

Allá va la negra negra, junto junto al español; anda y anda el barco barco con ellos dos.

Ich habe Ihnen die deutsche Übertragung von Erich Arendt vorgestellt, da sie wenn hier auch zeitbedingt von einer ,Negerin“ die Rede ist - Klang und Rhythmus, wie ich finde, sehr gut getroffen sind. Denn dieser „Son“ als kubanisch-karibische Musik- und Rhythmusform kann auch im Deutschen funktionieren, wenn man zugleich gut auf die Lexem-Rekurrenzen und deren Vokale achtet. Ziehen Sie bitte aber auch kurz die spanische Fassung heran!

Die von Beginn an absehbare Verbindung von schwarzem Mädchen und weißem Spanier auf einem schwarz-weißen Schiff in der Karibik, das zugleich aus Papier ist und auch als Schiff der Literatur gelesen werden kann, der Kampf von Schokolade (dunkel) und Zucker (weiß), Rhythmisierung und Verdoppelungen 
von Klängen im Kontext eines afrokubanischen Kinderlieds: All dies sind textuelle Elemente, welche die afrokubanischen Lyriker nicht frei erfunden, sondern in einer bestimmten Tradition gefunden haben, um sie sich dann kreativ anzueignen. Die Semantik wird sozusagen zu einer Konsequenz des Spiels mit den Vokalen. Gabriel de la Concepción Valdés - dies möchte ich mit Verweis auf die von ihm verwendete Formelhaftigkeit der Gottesattribute oder die Wendung mit den verdoppelten Königen betonen - ist in diese Tradition zu stellen! Denn auch sein Schiff hat einen weißen Spanier und eine schwarze Frau an Bord, wenn sich auch in seinem Falle die statistisch wesentlich seltenere Verbindung von Spanierin und Mulatten das Gefecht zwischen Schokolade und Zucker liefern.

All diese Verbindungen zwischen schwarz und weiß, deren Ergebnis in beiden Fällen das Dichtersubjekt selbst ist, vollziehen sich in einer Area, welche durch ihre Archipelhaftigkeit charakterisiert ist und wo sich im Meer der Antillen Insel an Insel reiht. Selbstverständlich war Nicolás Guillén sehr wohl über die Forschungen seines Landsmannes Fernando Ortiz im Bilde und wusste um jene Theorien, welche sich in Richtung einer Transkulturalität des Lebens auf den Antilleninseln entwickelten. Dabei zeichnet das Papierschiffchen zwanglos die Multirelationalität zwischen den Inseln nach und damit jenes Spiel von isolierter Insel-Welt und vielverbundener Inselwelt, das zu den Grundbedingungen allen Schreibens in der Area der Karibik zählt. ${ }^{12}$

Gabriel de la Concepción Valdés ist zweifellos der transkulturelle Großvater einer Lyrik, die es längst zu internationalem Ruhm und zu Literaturnobelpreisen gebracht hat; zählt die Area der Karibik doch nicht nur weltweit zu den Zonen verdichteter Globalisierung, sondern auch zu jenen Weltregionen, die sich durch eine ungeheuer hohe Konzentration an literarischer Aktivität auszeichnen. Ich möchte Ihnen daher auch noch ein zweites Gedicht von Gabriel de la Concepción Valdés vorstellen, das einen wesentlich weniger ernsten Status als seine Plegaria a Dios besitzt und vielleicht daher auch zu belegen vermag, dass er seinen Künstlernamen Plácido mit Bedacht gewählt hatte.

Es handelt sich um ein Gedicht, das den Titel Mi casa trägt und auf Grund seiner Länge nur auszugsweise vorgestellt werden kann. Diese Kreation lässt sich in die Tradition der Nicht-Orte stellen, repräsentiert aber freilich im Bachtin'schen Sinne eine Art Karneval dieses Lamartine'schen Nicht-Ortes, indem das populäre Element jenes der Hochkultur letztlich in Frage stellt und unverkennbar subvertiert:

12 Vgl. hierzu den Band von Ette, Ottmar / Müller, Gesine (Hg.): Caleidoscopios coloniales. Transferencias culturales en el Caribe del siglo XIX. Kaléidoscopes coloniaux. Transferts culturels dans les Caraïbes au XIXe siècle. Madrid - Frankfurt am Main: Iberoamericana - Vervuert 2010. 
Denen will ich, die mir Arbeit schaffen, (denn mein Unglück sind sie zuhauf), um Ärgernis sich zu ersparen weisen den Ort meines Hauses.

Ich geb keine Straße nicht an, denn wie der Marabu, so nomadisch, die Wüsten durchstreifend, sporadisch, mit seinem Zelte im Feld,

so zieh ich nicht selten umher, dreimal jede Woche gar, s'ist klüger und fällt mir nicht schwer, mein Anwesen hier zu skizzieren.

Angenommen mein Haus ist dasselbe, wo immer auch Plácido geht, gemalt wo ich heute lebe sind schon alle andern gemalt.

Wenn ihr erst mal ne Türe seht, die niemals verschlossen ist, weil drinnen niemals was ist, was sollte da Schlüssel noch Schloss? [...] Klar ist's, das Brot eines Dichters, wer reinzubeißen versucht, muss es erst mal in Wasser legen für dreieinhalb Stunden, jawohl! [...] Darum, und weil es mir füllt die Flasche, und keinen Morgen gibt's, an dem um Sonette nicht bittet für Olalla zum Gruße, und ach,

für Rita, für Rosa, für Petrona, für Celestina und Mariana zu Ehren ... Ein klitzekleines Sonettchen aus Décimas, die doch so schön. [...] Verschiedenste Kobolde besuchen mich und dieses Phantasma auch; Den einen soll ich was blechen, obgleich ich blank nun bin, 
die andern, die suchen Sonette, Tonnen von Sonetten sogar; sie geben mir nichts, sondern fordern, doch mach ich's gern, bin so nette. ${ }^{13}$ [...]

Quiero a los que me procuren (que hartos son mi desgracia) para evitarles molestias dar las señas de mi casa.

No indico calle ninguna, pues cual marabú que vaga errante por el desierto con su tienda de campaña,

suelo mudarme a ocasiones tres veces a la semana; y así tengo por más cuerdo bosquejarles mi morada.

Supuesto que ella es la misma doquier que Plácido vaya, pintando la que ahora vivo, están las demás pintadas.

Cuando veáis una puerta que jamás esté cerrada, porque donde nada queda ¿para qué llaves ni aldabas? [...] ¡No vio que el pan de un poeta, el que de morderlo trata, debe tenerlo primero tres horas y media en agua! [...] Por eso, y porque me llena la botella, no hay mañana que no me pida un soneto para saludar a Olalla,

13 Plácido: Poesías de Plácido, S. 23-28. 


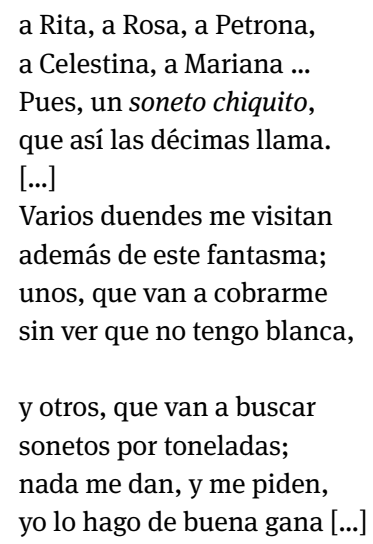

In diesem humoristischen Gedicht mit ernstem Hintergrund zeigt sich die bei Plácido stets beeindruckende Autoreflexivität ebenso auf Ebene des Biographischen, des Beruflichen wie des Literarischen, wobei diese drei Ebenen natürlich aufs Engste miteinander zusammenhängen. Denn das pikareske Element und das Nomadentum, die hier häusliche Grundausstattung und Wanderleben des armen Poeten kennzeichnen, haben selbstverständlich mit seinen unbefriedigenden Einkommensverhältnissen zu tun und mit der Tatsache, dass seine „décimas“ - und um diese populäre lyrische Form handelt es sich in diesem Gedicht ganz bewusst nicht genügend gewürdigt und bezahlt werden. Wie ich schon erwähnte, waren weite Strecken des Lebens von Gabriel de la Concepción Valdés von finanziellen Nöten und Engpässen geprägt, die ihn als freien Mulatten besonders hart trafen.

Auf humorvolle und zugleich sehr hintergründige Weise thematisiert sich Plácidos Auftragslyrik als Auftragslyrik selbst, verweist auf die prekäre finanzielle und wirtschaftliche Situation des Dichters innerhalb der kubanischen Gesellschaft und zeigt zugleich auf, dass Plácido sein Tun sehr wohl anders einschätzt und ihm einen höheren Stellenwert beimisst als seine zahlungsunwilligen Auftraggeber, die immer nur neue Gedichte von ihm verlangen. Die pikaresken Elemente, die wir auf dem amerikanischen Kontinent im Periquillo Sarniento von Fernández de Lizardi kennengelernt hatten, sind unübersehbar, so auch die Ausstattung seines Hauses (die ich etwas abkürzen musste) oder die ihn verfolgenden Gläubiger, die ihm unentwegt zusetzen. Ganz bewusst schreibt sich Plácido, der seinen Künstlernamen in das Gedicht aufnimmt, in eine pikareske Tradition in Lateinamerika ein, die wir spätestens mit Fernández de Lizardis Roman generisch verorten können, die aber in der Verbindung zwischen Pikareske und Autobiographie gerade in der karibischen Area sich etwa in Reinaldo Arenas' Antes que anochezca eindrucksvoll fortsetzt. 
Zugleich ist aber die Dichtkunst, die Lyrik, jenes Haus, das den Dichter beherbergt, der bisweilen über Land reisen muss; Reisen, bei denen der real existierende Plácido im Übrigen mehrfach gefangengenommen wurde und wiederholt im Gefängnis landete. In der Karibik spielt das Haus eine herausragende Rolle, überkreuzen sich doch in ihm die Vektoren von Bewegungsbahnen, welche die gesamte Area durchqueren und die einzelnen Teilregionen über die Inselgrenzen hinweg miteinander verbinden. ${ }^{14}$ Gabriel de la Concepción Valdés greift damit in seinem Gedicht ein zentrales Thema karibischen Schreibens auf, das sich vielleicht erst im 20. Jahrhundert voll entfaltete, bereits im 19. Jahrhundert aber von großer Bedeutung war, um die eigene Position des schreibenden Ich präzise zu konturieren und vektoriell zu verorten. In der Fraktalität des Hauses leuchtet etwas von der ebenfalls in sich abgeschlossenen Insularität auf und wird - in diesen Versen zumal - in eine unstete Vektorizität überführt, welche das Schreiben Plácidos aus der Marginalität im literarischen Feld Kubas begleitet.

Der Tonnen von Sonetten produzierende Dichter - dies zeigt das Gedicht auf witzige und ernste Weise zugleich - ist ein gesellschaftlicher Außenseiter. Diese Feststellung wird sich in der regionalen Lyrik des Río de la Plata wiederholen in der Figur des Gaucho, dem höchstens utilitäre Funktionen zuerkannt, aber nicht genügend vergolten werden. Damit nimmt der kubanische Dichter eine Thematik vorweg, die im Modernismo wiederholt von einem Lyriker wie Rubén Darío ausgeführt wurde. Plácido ist auf dieses Thema in seinen Gedichten mehrfach eingegangen; so etwa in einem Werk, in welchem der Dichter mit einem Kanarienvogel im Käfig gleichgesetzt wird und zum Singen verurteilt ist.

Bei Plácidos Dichtkunst handelt es sich folglich keineswegs um eine unreflektierte und nur verstechnisch geformte Lyrik, mithin um geschickt in Szene gesetzte, aber hinter der Rhetorik leere Handwerkskunst; sondern um literarische Ausdrucksformen, die ihre eigene Entstehung und ihre jeweiligen Entstehungs- und Rezeptionskontexte mit ins Spiel bringen. Mit Gabriel de la Concepción Valdés können wir ein weiteres Mal erkennen, wie auf klanglicher wie semantischer Ebene Elemente der europäischen Romantik in Hispanoamerika kreativ anverwandelt werden und in eine erst noch $\mathrm{zu}$ schaffende Bestimmung einer Romantik zwischen zwei Welten Eingang finden. Vor allem aber gelangt einer der von uns benannten kulturellen Pole mit diesem kubanischen Dichter zu zentralen Ausdrucksmöglichkeiten von dessen eigener Lage und Verortung,

14 Vgl. zu Rolle und Funktion des Hauses in der Karibik Ette, Ottmar: Von Inseln, Grenzen und Vektoren. Versuch über die fraktale Inselwelt der Karibik. In: Braig, Marianne / Ette, Ottmar / Ingenschay, Dieter / Maihold, Günther (Hg.): Grenzen der Macht - Macht der Grenzen. Lateinamerika im globalen Kontext. Frankfurt am Main: Vervuert Verlag 2005, S. 135-180. 
seines Schreibens aus einer unverkennbaren Marginalität. Diese Möglichkeiten machen auf literarische Weise ihre Randständigkeit nicht nur zu einem Thema, sondern führen und schreiben zugleich neue Metriken und Rhythmen, eine neue Musikalität in die Dichtkunst des 19. Jahrhunderts mit weit in das 20. Jahrhundert weisenden Folgen ein. 